Fanum

Sociológico

\section{Forum Sociológico}

Série II

33 | 2018

Número 33

\title{
Gandhi vs. Savarkar e Golwalkar : Secularismo pan- indiano e fundamentalismo hindu
}

Gandhi vs. Savarkar and Golwalkar: Pan-Indian Secularism and Hindu

Fundamentalism

Pedro Matias Santos

\section{CpenEdition}

Journals

Edição electrónica

URL: https://journals.openedition.org/sociologico/2538

DOI: 10.4000/sociologico.2538

ISSN: 2182-7427

Editora

CICS.NOVA - Centro Interdisciplinar de Ciências Sociais da Universidade Nova de Lisboa

Edição impressa

Paginação: 29-36

ISSN: 0872-8380

\section{Refêrencia eletrónica}

Pedro Matias Santos, «Gandhi vs. Savarkar e Golwalkar : Secularismo pan-indiano e fundamentalismo hindu», Forum Sociológico [Online], 33 | 2018, posto online no dia 30 dezembro 2018, consultado o 29 março 2022. URL: http://journals.openedition.org/sociologico/2538; DOI: https://doi.org/10.4000/ sociologico. 2538 


\title{
GANDHI VS. SAVARKAR E GOLWALKAR: SECULARISMO PAN-INDIANO E FUNDAMENTALISMO HINDU
}

\section{GANDHI VS. SAVARKAR AND GOLWALKAR: PAN-INDIAN SECULARISM AND HINDU FUNDAMENTALISM}

\author{
Pedro Matias Santos \\ ISCSP - Instituto Superior de Ciências Sociais, Universidade de Lisboa \& Instituto do Oriente, Instituto Superior de \\ Ciências Sociais, Universidade de Lisboa, Portugal
}

\begin{abstract}
Resumo
Este artigo pretende dar um contributo para a análise do nacionalismo indiano, quer sob a forma do nacionalismo pan-indiano alicerçado no secularismo, tal como foi definido por Gandhi, quer sob a forma do nacionalismo hindu alicerçado no fundamentalismo, tal como foi definido por outras duas figuras políticas, Savarkar e Golwalkar. As duas ideologias serão tratadas tanto no contexto do período colonial como mais tarde, na sequência da sua reactualização nas agendas políticas dos dois principais partidos políticos no período pós-colonial da Índia, o Congress Party (CP) (Partido do Congresso) ou Indian National Congress (INC) e o Bharatiya Janata Party (BJP) (Partido do Povo Indiano) e o seu braço armado (RSS).
\end{abstract}

Palavras-chaves: fundamentalismo hindu, secularismo pan-indiano, Gandhi, Savarkar, Golwalkar

\begin{abstract}
This paper aims above all to make a contribution to the analysis of Indian nationalism either in the form of Pan-Indian nationalism based on secularism as defined by Gandhi or in the form of Hindu nationalism grounded in Hindu fundamentalism, as defined by two other political figures, Savarkar and Golwalkar, both in the context of the colonial period and later as a result of their revival in the political agendas of the two main political parties in the post-colonial period of India, the Congress Party (CP) or Indian National Congress (INC) and the Bharatiya Janata Party (BJP) (Indian People's Party).
\end{abstract}

Keywords: Hindu fundamentalism, Pan-Indian secularism, Gandhi, Savarkar, Golwalkar

"L'Inde derive rapidement vers le nationalisme et le fascisme"

"Le parti du Premier ministre indien Narendra Modi reproduit de manière claire I'organisation même du parti nazi"

Rushdie, 2017, p. 14

\section{Introdução}

O objectivo deste artigo consiste em analisar o modo como o secularismo pan-indiano de Gandhi e o fundamentalismo hindu de Savarkar e Golwalkar, tal como foram construídos no contexto do nacionalismo indiano (Cf. Jaffrelot, 2007), foram determinantes nas agendas actuais dos dois principais partidos políticos da República da Índia: o Congress Party (CP) e o Bharatiya Janata Party (BJP), especificamente no que diz respeito ao conflito entre as comunidades religiosas hindu e muçulmana (Cf. Brass, 2003). ${ }^{1}$ Assim, o objectivo principal consiste em compreender o enquadramento historiográfico do período pré-colonial, partindo do pressuposto de que não se pode entender a política na Índia sem entender o modo como a religião se expressou neste 
contexto, mesmo quando a Constituição Indiana afirma o secularismo como princípio estruturante do Estado; num segundo momento, pretendemos também analisar as obras mais importantes de Gandhi, Savarkar e Golwalkar, e verificar como o fundamentalismo hindu e o secularismo pan-indiano foram construídos por estes ideólogos durante o período colonial; num terceiro momento, analisar a relação entre as ideologias do fundamentalismo hindu e do secularismo pan-indiano e as agendas dos principais partidos políticos da Índia pós-colonial.

A análise histórico-sociológica das ideologias do secularismo pan-indiano e do fundamentalismo hindu inerentes ao nacionalismo da Índia colonial e pós-colonial enquadra-se no ramo disciplinar da Sociologia Histórica.

Partimos da Sociologia ao escolher o modelo teórico, o modelo construtivista, e recorremos à História Nova de longue durée inspirada na leitura de Grammaire des Civilisations de Fernand Braudel (1989). Recorro ainda a outras Ciências Sociais, como a Antropologia e a Ciência Política, e a áreas de estudo como a etnicidade, o nacionalismo, e conflito étnico, a ideologia, o secularismo e o fundamentalismo, e ainda os estudos pós-coloniais.

Pretende-se que o contributo seja o de analisar as ideologias traçadas por Gandhi, Savarkar e Golwalkar e perceber o impacto que estas ideologias tiveram nas agendas dos dois maiores partidos políticos na Índia, no contexto do nacionalismo colonial e pós-colonial, e dar a conhecer a forma como as relações entre as comunidades mais significativas da Índia, a hindu e a muçulmana, são determinantes nas questões referidas. Este trabalho situa-se entre a Sociologia e a História, com uma abordagem situada no vasto domínio do construtivismo (Berger \& Luckmann, 1991) - que nos propõe estudar a realidade humana como uma realidade socialmente construída. Esta obra é fundamental, sobretudo porque será o construtivismo social o modelo teórico que irá sustentar este trabalho.

Esta abordagem teórica defende que se deve dar lugar à análise dos processos pelos quais se dá a construção subjectiva da realidade social, i. e., como ela é concebida simbolicamente quer pelo objecto quer pelo sujeito de estudo, e como esta é constantemente criada e recriada pelos agentes sociais, considerados estes não apenas e meramente produtos da sociedade, mas também, como aqueles, construtores da realidade social.

$\mathrm{E}$, assim, apelando à transdisciplinaridade no contexto da sociologia histórica contemporânea (Steinmetz, 2007, p. 8) que recorre a diversas Ciências Sociais para estudar um determinado fenómeno social. Das fontes primárias seleccionadas, escolhemos, por um lado, os textos relativos ao secularismo no contexto do nacionalismo indiano, Hind Swaraj, "que é a melhor introdução do seu pensamento"
(Nussbaum, 2007, p. 97) e uma compilação de Dalton (1996) dos principais documentos produzidos pelo ecuménico Gandhi (1869-1948), que é considerado "o pai do secularismo indiano" (Madan, 1993, p. 675). Em complementaridade recorremos a textos de Savarkar (1883-1966), Hindutva: Who is a Hindu? (1989) e The Gandhian confusion (1927), e de Golwalkar (1906-1973), We or our nationhood defined (2006) e Bunch of thoughts (2000). Estes autores sistematizaram, quer teórica quer programaticamente, o fundamentalismo hindu a partir da década de 1920 (Mendes, 2009; Nussbaum, 2007, p. 156; Panikkar, 1999, p. xi; Puniyani, 2005, p. 17).

Posto isto, pretende-se estudar a forma como os mais destacados promotores das ideologias do secularismo pan-indiano e do fundamentalismo hindu, assim como os líderes do BJP e do CP que reactualizam os dois projectos, acabam por instrumentalizar elementos culturais, religiosos e linguísticos no sentido de levar a cabo uma mobilização étnica e política.

Nesse sentido, verifica-se neste país, desde a independência, uma verdadeira bipolarização partidária, que tem posturas diferentes em relação ao conflito profundo entre as comunidades religiosas hindu e muçulmana, tendo como um dos palcos de disputa privilegiado a mesquita de Ayodhya, que constitui ainda hoje metonímia do comunalismo na Índia (Van der Veer, 1987, pp. 284-285). Desde a independência da Índia em 1947, os valores democráticos sobreviveram apesar de certas irregularidades na sua prática, demonstrando a resiliência do secularismo neste país. A escolha colectiva do secularismo é, em grande parte, influenciada pela forma como a sociedade indiana foi historicamente constituída, com um grande número de religiões, o que fez da Índia um Estado com diferentes religiões cujo conflito foi atiçado durante o período colonial britânico. Apenas com o secularismo, como um imperativo moderno, poderá sobreviver a prática da democracia. Embora os valores do secularismo tenham sido postos em causa durante o período em que o BJP esteve no governo, período em que os direitos das minorias foram constrangidos, a nova subida ao poder do CP permitiu restabelecer esses valores (Cf. Nussbaum, 2007, p. 330).

De facto, não se pode compreender a política indiana sem compreender a questão da religião. Por um lado, pode ser visto o conflito entre hindus e muçulmanos como resultante de uma continuidade passado-presente, remontando ao início da ocupação muçulmana; por outro lado, o conflito pode ser entendido como datando de um período mais recente, moderno, para o que os britânicos com a sua política de Divide and Rule muito contribuíram. Mas o conflito também foi accionado quer pelos muçulmanos quer pelos hindus fundamentalistas de uma forma instrumental para atingir fins políticos específicos (Cf. Brass, 2003, p. 25). 


\section{Gandhi vs. Savarkar e Golwalkar}

Da análise feita do corpus empírico, constituído por textos de Gandhi, como secularista pan-indiano, e de textos dos fundamentalistas hindus Savarkar e Golwalkar, pudemos concluir o seguinte:

Quanto aos fins a atingir, Gandhi defende a constituição de uma Índia pluralista e secular, porque a Índia não deixa de ser uma nação só porque há pessoas pertencentes a outras religiões que não o Hinduísmo. Elas confluem num mesmo sentido. A Índia deve ter a capacidade de assimilar os estrangeiros e, segundo Gandhi, este país demonstrou-a sempre. Neste sentido, Gandhi recusa uma Índia exclusivamente hindu, uma Índia monocultural e, sobretudo, religiosamente unívoca; defende, sim, uma Índia tolerante, em que todas as religiões seriam igualmente respeitadas, acentuando a radical universalidade de todas as religiões. Como tal, Gandhi considerou como direitos fundamentais de uma futura constituição, entre outros, o sufrágio universal - de modo a garantir uma democracia - e a neutralidade religiosa por parte do Estado, pois apenas e só um Estado laico poderia prevenir o comunalismo e assegurar a igualdade entre as diferentes comunidades religiosas da Índia, garantindo o rico mosaico que a Índia sempre foi. O espírito ecuménico seria a trave-mestra da Índia independente, posto que Gandhi não defendia a reconversão dos não-hindus e privilegiava, pelo contrário, a riqueza da diversidade religiosa. Neste sentido pluralista, o Bhagavad-Gita, o Alcorão e a Bíblia seriam textos religiosos para todos os indianos, independentemente da religião de que façam parte (Cf. Gandhi, 2011; Gandhi in Dalton, 1996).

Quanto aos meios, Gandhi defende estratégias cívicas e políticas. Só estas conseguiriam alcançar fins justos, daí que o melhor meio fosse satyagraha, ou o "poder da verdade". Gandhi procurou encontrar uma legitimação religiosa para fundamentar esta forma de resistência passiva inovadora e o texto mais importante a que recorreu foi o Bhagavad-Gita, o livro mais sagrado do Hinduísmo. O Bhagavad-Gita corresponde - qual Fédon hindu - à revelação de Krishna a Arjuna acerca da mortalidade da alma individual [atman], fazendo esta parte da alma universal [brahman], a realidade última, Deus. Este foi para Gandhi o texto mais importante, pois afasta-nos da ilusão (maya) da separação dos seres vivos e dá-nos, em contraponto, a ideia de união de todos eles, o que implica que exercer violência sobre outro indivíduo (himsa) é exercer, em última instância, violência sobre si próprio. Assim sendo, tendo como fim o swaraj (liberdade política), o meio para o atingir é o satyagraha (o poder da verdade), sendo o ahimsa (a não-violência) uma das mais importantes verdades universais (Cf. Gandhi, 2011; Gandhi in Dalton, 1996).
Já os dois fundamentalistas hindus que analisámos sistematizam de forma clara e inequívoca um Estado-Nação hindu monolítico, cujas fronteiras físicas coincidiriam com as fronteiras étnica, religiosa e linguística da comunidade hindu. Savarkar (1927; 1989) e Golwalkar (2000; 2006) deram definições semelhantes do que é ser hindu. Enquanto Savarkar define esta identidade a partir de uma fórmula com três critérios (nação + raça + cultura), Golwalkar fê-lo com cinco (país + raça + religião + cultura + língua), sendo que os três últimos podem ser incluídos no terceiro e último, isto é, a cultura ou sanskriti, como Savarkar refere.

Para definir o rashtra (a nação), Savarkar remonta ao período em que os hindus teriam feito das margens do rio sagrado Sindhu - o mais importante de todos os rios - a sua terra, região onde se teriam cruzado com tribos locais; a miscigenação daí resultante teria dado origem aos actuais hindus. As fronteiras vão desde o rio Indo ao Golfo de Bengala e dos Himalaias a Ceilão. Mas mais do que isso: Savarkar faz coincidir a pátria com a Terra Santa, isto é, um hindu, além de considerar a Índia sua pátria, também a considera a sua Terra Santa. Já não será o caso dos muçulmanos ou dos cristãos, que podem ter uma mesma pátria, mas não uma mesma Terra Santa, Meca ou Jerusalém, respectivamente.

Golwalkar, por sua vez, considera a existência de um território como algo indispensável, pois na ausência deste as comunidades entrariam em diáspora, como é o caso dos parsis, cujo território inicial era a Antiga Pérsia, que corresponde actualmente ao Irão. Para Golwalkar, então, o primeiro requisito para a constituição de uma nação é um pedaço de terra delimitado preferencialmente por limites naturais. Que o povo que vive nessa terra a considere a sua deusa-mãe, sentindo-se filho daquele solo, é um imperativo incontornável.

O segundo critério, a raça, é para Golwalkar o mais importante. Se há estrangeiros, eles devem miscigenar-se com os hindus. O casamento misto é, nestes casos, condição fundamental para se tornar hindu. Para Savarkar, os hindus resultaram do cruzamento entre arianos e não-arianos, isto é, dravidianos e tribais, pertencentes a todas as castas, desde os brâmanes aos intocáveis. Segundo ele, também é possível que um estrangeiro se torne hindu, conquanto se case com uma pessoa hindu e cumpra os outros dois critérios por ele definidos.

De acordo com Savarkar e no que diz respeito à cultura, para se ser hindu é necessário ter-se uma ligação afectiva à civilização hindu, que designa de Sanskriti. A religião hindu ou Hindu Dharma, na sua acepção, corresponderia ao conjunto das religiões que tiveram a sua revelação em terras da Índia e com origem nos Vedas: o Santan Dharma, o Sikh Dharm, - AryaDharm, o JainDharm, e o AryasamajisDharm. 
Para Golwalkar, religião e cultura estão interligadas, pois no Hindustão (forma de designação do subcontinente indiano na altura da colonização britânica) não são distinguíveis uma da outra, já que a religião permeia cada acto quotidiano do hindu. E, como tal, o Hinduísmo (Sanatana Dharma) deveria ser adoptado como religião oficial de Estado.

A superioridade da cultura hindu perante as culturas ocidentais materialistas decorre da circunstância de os filósofos hindus antigos terem transcendido o materialismo e descoberto a realidade última que atravessa toda a criação, deus. De acordo com o mito da criação do mundo nas Leis de Manu, Purusha (Homem, Homem cósmico, uma das formas de designar o Absoluto) desmembra-se no sentido das quatro varnas (Cf. Biardeau, 1995). Aliás, o verdadeiro objectivo de vida de um hindu é o serviço à Humanidade, pois é em última instância serviço a deus - o que Golwalkar considera que deveria ser o traço fundamental da vida hindu.

Ainda segundo Golwalkar, os indivíduos pertencentes à nação hindu não devem ser heterogéneos, devem ter um modo de vida, com ideias, cultura, sentimentos, fé e tradições comuns, um verdadeiro Estado-Nação, e, neste sentido, acusou Gandhi de promover a unidade hindu-muçulmana, que levaria à criação do Paquistão e à partição da Terra-Mãe.

Se os projectos de Gandhi e dos fundamentalistas hindus, Savarkar e Golwalkar, são diametralmente opostos, apresentam, no entanto, alguns aspectos em comum: a questão da língua, a questão do sistema de castas, a questão da rejeição do estilo de vida ocidental.

No que diz respeito à língua, Savarkar afirma que o hindi seria a língua por excelência do futuro Estado da Índia, previsão com a qual Golwalkar também concorda, por se tratar de uma das línguas mais faladas de toda a Índia. Também Gandhi concorda, com a ressalva de que a língua oficial seja escrita quer no alfabeto devanagari, derivado do sânscrito, quer no alfabeto árabe, alfabetos que deveriam ser aprendidos por todos os indianos para promover o espírito de tolerância.

Quanto à rejeição do sistema de castas, Savarkar é claramente contra a discriminação em função da casta, assim como Golwalkar. Quer quanto à intocabilidade em particular, quer quanto à hierarquia do sistema de castas em geral, dever-se-iam promover os casamentos entre as várias castas, a comensalidade e ainda a celebração das práticas religiosas em comum (Gandhi in Dalton, 1996). Para Gandhi, a própria varnashrama (divisão da sociedade em quatro varnas), inscrita nos Vedas, deveria ser abolida, devendo desde logo ser possível o casamento e a comensalidade entre as quatro varnas. Gandhi passou a designar os párias por Harijans, ou seja, "filhos de deus". Gandhi também se destacaria pela defesa da mudança do estatuto social tradicional da mulher indiana, questão que não foi tratada pelos fundamentalistas (Gandhi in Dalton, 1996).

Em último lugar, todos rejeitam o estilo de vida ocidental. Para os fundamentalistas, a vida quotidiana deveria pautar-se de acordo com o Dharma, o código universal de conduta. Golwalkar é clara e inequivocamente contra o secularismo, pois este teve a sua origem no Ocidente, e não tem relevância para o hindu rashtra. Já Gandhi considerava impreterível a proclamação de um Estado secular para garantir a harmonia entre as diversas religiões presentes na Índia.

Ora, em contraponto a Gandhi, os fundamentalistas hindus tomam, neste aspecto, claramente uma posição oposta, defendendo a lei de Talião. Golwalkar socorre-se da figura histórica e paradigmática de Shivaji, o herói maratha. Golwalkar considerava Bharat, a Terra Santa, uma manifestação da Deusa-Mãe e considerava também que a forma de devoção mais dinâmica à Deusa-Mãe era a de um verdadeiro sacrifício pela vida nacional, derrotando os demónios (e assim foram associados simbolicamente aos demónios os não-hindus, estes últimos definidos por exclusão de partes, designadamente, britânicos, muçulmanos e sikhs).

Savarkar legitima também o recurso à violência, recuando ao período búdico da história da Índia, que permitiu, segundo ele, a difusão dos hindus por grande parte do mundo, mas que também foi responsável pela sua queda, na medida em que eles sucumbiram ao ataque de estrangeiros por não tendo retaliado, apenas recitando mantras, fórmulas de ahimsa e de amor fraternal. Em The Gandhian confusion, Savarkar (1927), além de resgatar Shivaji, critica abertamente o satyagraha, denunciando inclusivamente a conivência mais ou menos tácita com os muçulmanos. Savarkar refere que, num acto de autodefesa, o recurso à violência, até mesmo ao assassínio, é um acto legítimo sancionado pelas Leis de Manu, isto é, pela religião. ${ }^{2}$

Apesar de nos textos analisados os fundamentalistas hindus Savarkar e Golwalkar apresentarem uma lacuna no que diz respeito à posição da mulher hindu, os fundamentalistas hindus são, a este respeito, bastante conservadores, considerando as mulheres guardiãs por excelência da tradição religiosa, como nos relata Sarkar:

In the area of women's conditions, the fore grounding of women politicians of BJP are aligned to paeans of praise to traditions of brahmanical Hinduism, and to occasional fundamentalist pronouncements even by their women leaders which applaud sati, criticize women's employment, divorce and widow remarriage and flay rebellious sexual preferences like lesbianism. (Sarkar [sic], 1999, p. 138) 


\section{Secularismo pan-indiano e fundamentalismo hindu}

O primeiro líder da Índia após a independência, Jawaharlal Nehru, que promoveu um Estado secular e tolerância para com os muçulmanos da Índia, disse que era "totalmente falacioso falar da cultura indiana como cultura hindu".

O RSS defende que os antepassados de todas as pessoas de origem indiana - incluindo os 172 milhões de muçulmanos - eram hindus, e que têm de aceitar estas raízes comuns como parte de Bharat Mata, ou Mãe Índia. Modi é membro de RSS desde a infância.

Rupam \& Lasseter, 2018

Para dar conta do secularismo pan-indiano e, sobretudo, do fundamentalismo hindu e da posição tomada pelo RSS, braço armado oficioso do BJP, o ex-embaixador português na Índia, Luís Filipe Castro Mendes, refere:

É que, nos anos 20 do século passado, os ideais da "raça pura ariana" entusiasmaram alguns intelectuais indianos, de que se destacaram Savarkar e Golwalkar, fundadores do RSS (movimento de extrema-direita hinduísta, baseada na ideia do "Hindutva", como núcleo essencial redescoberto da complexa religião hindu). Para esta corrente de pensamento, tudo o que não fosse de pura substância hindu, tudo o que não fosse conforme ao reinventado "Hindutva", não poderia ser indiano: por isso, cristãos, judeus e muçulmanos (recorde-se que a Índia tem a segunda maior população muçulmana do mundo) apenas poderiam residir na Índia por generosidade dos hindus, mas nunca poderiam pertencer à sua comunidade nacional - e aqui temos ao mesmo tempo o ideal oitocentista do Estado - Nação homogénea e a ideia de civilização como identidade estanque, cara a Huntington! (Mendes, 2009). ${ }^{3}$

Sendo Gandhi considerado "o pai espiritual do secularismo indiano" (Madan, 1993, p. 675), uma questão última se coloca, que é a seguinte: qual poderá ser o futuro do secularismo na Índia? A adição das palavras "secular" e "socialista" à descrição da Índia como uma República soberana, no preâmbulo da Constituição, deveu-se à emenda número 42, datada de 1976, durante o "Emergency rule" de Indira Gandhi, embora a constituição já admitisse que a Índia, de uma forma tácita, constituía um Estado secular (Cf. Madan, 1993, pp. 682-684).
T. N. Madan, editor de Contributions to Indian Sociology, faz em 1987 um prognóstico bastante reservado quanto ao futuro do secularismo na Índia, como se a democracia secular neste país estivesse em risco, dada a forte militância hindu (Cf. Malik \& Vajpaeyi, 1989):

Now, I submit that in the prevailing circumstances secularism in South Asia as a generally shared credo of life is impossible, as a basis for state action impracticable, and as a blueprint for the foreseeable future impotent. It is impossible as a credo of life because the great majority of the people of South Asia are in their own eyes active adherents of some religious faith. It is impracticable as a basis for state action either because Buddhism and Islam have been declared state or stateprotected religions or because the stance of religious neutrality or equidistance is difficult to maintain since religious minorities do not share the majority's view of what this entails for the state. And it is impotent as a blueprint for the future because, by its very nature, it is incapable of countering religious fundamentalism and fanaticism. (Madan, 1987, p. 748)

Mas o secularismo, segundo Bhargava (2010b), parece estar en état de siège em todo o lado, principalmente desde o estabelecimento da primeira teocracia moderna no Irão de Khomeini em 1979:

Soon other religious voices began to be heard and then to aggressively occupy the public domain. In Egypt, people were urged to free themselves of the last vestiges of a colonial past to establish a Muslim state. In 1989, an Islamic state was established in Sudan. In 1991, the Islamic Salvation Front won the election in Algeria. Islamic movements emerged in Tunisia, Ethiopia, Nigeria, Chad, Senegal, Turkey and Afghanistan (...). The state of Pakistan increasingly acquired theocratic and Islamicist overtones. (Bhargava, 2010b, p. 82)

A verdade é que tais movimentos não são exclusivos das sociedades muçulmanas; só no contexto do subcontinente indiano encontramos três exemplos paradigmáticos de uma crise do secularismo: os nacionalistas hindus tâmiles no Sri Lanka, os nacionalistas hindus e os nacionalistas sikhs na Índia.

De acordo com o ex-primeiro ministro da Índia, Atal Behari Vajpayee, o pseudo-secularismo deveria ser banido, posto que Bharat Mata (Mãe Índia) é uma unidade cultural que deve corresponder a uma unidade política económica e social, cuja corrente de vida tem vindo a florescer desde os tempos 
védicos, e a única solução para o comunalismo é o despertar de um forte sentimento de nacionalismo. O Dharma é uma forma de vida ancestral e não pode ser separado da constituição do Estado hindu (Vajpayee, 2007, pp. 315-341).

Mas também no Ocidente se passa o mesmo, quer nos Estados Unidos com o crescimento do fundamentalismo cristão protestante, quer nas sociedades europeias pluriculturais como a Grã-Bretanha, a Alemanha e, sobretudo, a França, dada a presença de comunidades muçulmanas que põem em causa o modelo monolítico de referência de Estado-Nação.

Para Malik \& Vajpeyi (1989) a garantia do secularismo na Índia passa pelo seguinte:

The challenges presented by nationalism, secularism, and communalism to the process of nation-building in India can be met only if the Indian state remains strong, viable, and democratic; if it can manage external and internal pressures; and if long-expected secularization of the population takes place through education, modernization, political development, expansion of economic resources and national integration. (1989, p. 325)

Recuperando o espírito de Gandhi, T. N. Madan (1993) sustenta que as várias tradições religiosas na Índia são "membros de uma mesma família" (Madan, 1993, p. 696). Havendo semelhanças entre o Hinduísmo, o Sikhismo, o Jainismo e até o Cristianismo e o Islão indianos:

They share crucial metaphysical presuppositions about "being", "knowing" and "value", contribute significantly to the encompassing cultural ambiance of the country, and provide the foundation for India's regional composite cultures. Their followers share many attitudes and have many social practices in common. (Madan, 1993, p. 696)

O comunalismo é a questão do conflito entre as comunidades religiosas da Índia, das quais destacamos neste artigo as duas mais significativas, a comunidade hindu e a comunidade muçulmana. A primeira é maioritária, com mais de $80 \%$ da população, e a segunda tem cerca de $10 \%$. A restante percentagem da população da União Indiana divide-se pelas restantes cinco comunidades religiosas existentes: os parsis (ou zoroastrianos), os budistas, os jainistas, os sikhs e os cristãos, constituindo esta uma questão tout à fait actual nas agendas políticas dos partidos políticos (Cf. Elst, 1990, p. 1; Hanson, 1999; Nussbaum, 2007). ${ }^{4}$

Mas, começando por aceitar as semelhanças no contexto do pluralismo cultural da sociedade indiana contemporânea (Juergensmeyer, 1996, p. 134; Madan, 1993, p. 697), a concepção de secularismo pan-indiano não é, de todo, uma parede de separação entre religião e Estado, como acontece no Ocidente, mas antes um tratamento igual e proporcional de todas as fés que pertencem a uma mesma árvore que é Deus (Wright Jr., 2001, pp. 1-2). Esta particularidade do secularismo pan-indiano pode até servir de lição a uma laïcité francesa ou a um secularismo liberal americano na acepção de Thomas Jefferson (Bhargava, 2010a, pp. 101-109).

Depois das eleições de 2014, podemos, na continuidade de Corbridge \& Harriss (2008), acrescentar um quarto momento decisivo em que a Índia se reinventa, de novo, no sentido do que me atrevo cunhar o termo - na linha argumentativa de Hanson (1999) - de uma "Second Saffron Wave", pendendo a Índia mais uma vez no sentido do fundamentalismo hindu defendido pelo BJP, agora liderado por Narendra Modi e, desta feita, com a maioria absoluta dos lugares do Lok Sabha ${ }^{5}$. Não é por acaso que Salman Rushdie afirma que a Índia, a maior democracia do mundo, é hoje uma ditadura (2017, p. 14).

Será que a maioria no Lok Sabha por parte do BJP poderá agudizar ainda mais as relações entre a comunidade hindu e a comunidade muçulmana dentro das fronteiras da União India? Assim como poderá dificultar as relações deste Estado constitucionalmente laico com o Estado teocrático vizinho da República Islâmica do Paquistão, tal como aconteceu na primeira "Saffron Wave", em que o BJP formou governo e imediatamente nos dias seguintes mandou explodir bombas atómicas perto da fronteira com o Paquistão? Não será um desafio aguardar e escrever posteriormente um livro que actualize este, no que diz respeito à contemporânea "Second Saffron Wave"?

Em jeito de conclusão, a Índia continua a ser a maior democracia do mundo, cujo secularismo tem vingado pela sua resiliência, mesmo depois da primeira "Saffron Wave", tendo o seu nacionalismo contemporâneo como referência elementos simbólicos de ordem histórica, cultural, religiosa e linguística que constroem uma identidade étnica indiana. Podemos agrupar esses elementos de acordo com o modelo construtivista, por um lado numa leitura mais instrumentalista e por outro lado numa leitura mais primordialista.

No que diz respeito a uma leitura mais instrumentalista, temos a luta de décadas contra a ocupação britânica, que definiu por exclusão a identidade indiana; numa leitura mais primordialista e por inclusão, temos a figura histórica de Gandhi como Bapuji, considerado o pai da nação indiana, o Taj Mahal, onde os noivos indianos passam a sua lua-de-mel, o cricket como desporto nacional e, sobretudo, os filmes contemporâneos de Bollywood, a maior 
indústria cinematográfica do mundo, transmitidos em hindi (com música bhangra, música do Punjab, e uma masala de vários estilos musicais, até ocidentais, hip hop). Estes filmes são vistos cada vez mais por homens e mulheres de todas as gerações, por todas as castas da comunidade hindu e demais comunidades religiosas que pertencem, no seu conjunto, a uma nova Nação que tem vindo a reinventar-se sucessivamente (Lichter \& Bandyopadhyay, 2008). Os filmes de Bollywood em hindi poderão contribuir para uma homogeneização cultural e linguística da Índia, quando até agora o hindi era considerado pelos Estados do Sul do subcontinente indiano que falam línguas dravidianas, que nada têm que ver com a família linguística indo-europeia do Norte com origem no sânscrito, "a northern language", razão pela qual preferiam falar em inglês com um indiano do Norte do subcontinente, como forma de resistir à hegemonia das línguas do Norte da Índia que é imposta de acordo com agendas nacionalistas da imposição de uma língua nacional, falada por todos, qual Hexógono. A tendência da nova geração de indianos será aprender a falar fluentemente várias línguas: a língua-mãe do Estado de origem, o hindi e o inglês; é precisamente dessa forma que está organizado o sistema de ensino básico e secundário na Índia. Se a língua do mercado é a língua local, o inglês é a língua dos negócios e da academia indiana, e o hindi, a língua mais falada da Índia e que se concentra no "hindi belt" do Norte da Índia, e a língua dos filmes de Bollywood.

\section{Conclusão}

A Índia contemporânea é uma sociedade plural, não é um Estado-Nação, não no sentido ortodoxo que parte de pressupostos oitocentistas de uma homogeneidade cultural, religiosa e linguística do Hexágono monolítico, mas corresponde antes a uma civilização mais extensa; não a uma civilização hindu tout court, como Huntington defendia, por demais redutora, mas sim a uma civilização indiana. Sendo esta civilização bem mais ampla, tendo como horizonte a vastidão imensa da Deusa, mãe de todos os deuses e de todos os seres humanos.

Gandhi foi a figura de proa do secularismo, defendendo o nacionalismo pan-indiano, assim como Savarkar e Golwalkar o foram do fundamentalismo hindu, defendendo o nacionalismo hindu. Estes projectos definidos em pleno contexto do período colonial foram depois reactualizados nas agendas políticas dos dois principais partidos políticos no período pós-colonial da Índia, o CP e o BJP.

De facto o $\mathrm{CP}$, defensor do secularismo pan-indiano, inspirou-se na ideologia definida por Gandhi, a da constituição de um Estado secular pan-indiano por meios pacíficos, e o BJP, defensor do fundamentalismo hindu, inspirou-se na ideologia definida por
Savarkar e Golwalkar, a da constituição de um Estado teocrático hindu por meios de militância armada.

Neste sentido, os principais ideólogos do secularismo pan-indiano e do fundamentalismo hindu e os líderes do CP e do BJP/RSS instrumentalizam elementos culturais, religiosos e linguísticos no sentido de levar a cabo uma mobilização étnica e com vista à obtenção do poder.

\section{Notas}

1 Refira-se que, tendo começado o trabalho com o acordo ortográfico anterior, preferi mantê-lo.

2 Para uma leitura em torno das Leis de Manu, veja-se Leis de Manu (1992).

3 Leia-se o artigo de Saïd (2002), uma das figuras impulsionadoras dos estudos pós-coloniais, que faz uma crítica clara e inequívoca a O Choque das Civilizações e a Mudança na Ordem Mundial de Huntington (1999), que por sua vez criticara a tese de Fukuyama (1999), que defende que, depois de 1989, com a queda do Muro de Berlim e o massacre dos estudantes na Praça de Tiananmen em Beijing, os Estados ocidentais e não ocidentais rumariam à união pacífica com a adopção da democracia e do capitalismo. Em "O Choque das Ignorâncias", Saïd (2002) considera que o 11 de Setembro não é a prova provada da tese de Huntington, isto é, de um choque entre a civilização ocidental e a civilização islâmica, pois não se tratou de um ataque do Islão en masse contra os EUA, mas sim de um ataque perpetrado por uma célula terrorista, ataque no qual muitos países islâmicos não se reviram; assim como põe em causa as ideias da homogeneidade $e$ enquistamento das civilizações definidas por Huntington, na senda de Braudel, como é o caso designado de uma civilização hindu, quando a União Indiana é constituída não apenas por hindus, mas por outras comunidades étnicas, como é o caso dos muçulmanos, dos parsis, dos cristãos, dos sikhs, dos budistas e dos jainistas.

4 De acordo com o mais recente censo, de 2001, o Hinduísmo corresponde a $80,5 \%$ da população, o Islão a $13,4 \%$, o Cristianismo a $2,3 \%$, o Sikhismo a $1,9 \%$, o Budismo a $0,8 \%$, o Jainismo a $0,4 \%$, sem religião declarada a $0,1 \%$, e o restante $0,6 \%$ a outras religiões como o Zoroastrianismo, o Bahá'í e o Judaísmo (Ver: http:// www.censusindia.gov.in/Tables_Published/C-Series/CSeries_link/c15_india.pdf). Note-se que a Índia é o terceiro país mundial com maior percentagem de muçulmanos, depois da Indonésia e do Paquistão, seguindo-se imediatamente o Bangladesh, sendo que se encontram situados na região da Ásia do Sul e do Sudeste Asiático insular justamente os países com populações muçulmanas mais significativas.

5 Câmara baixa do Parlamento da Índia.

\section{Referências bibliográficas}

Berger, P., \& Luckmann, T. (1991 [1966]). The social construction of reality: A treatise in the sociology of knowledge. Londres: Penguin Books.

Bhargava, R. (2010a). The distinctiveness of Indian secularism. In A. S. Rathore \& S. Mohapatra (Eds.), Indian political thought: A reader (pp. 99-120). Londres: Routledge. 
Bhargava, R. (2010b). Political secularism: Why is needed and what can be learnt from its Indian version. In G. B. Levey \& T. Modood (Eds.), Secularism, religion and multicultural citizenship (pp. 101-109). Cambridge: Cambridge University Press.

Biardeau, M. (1995 [1981]). L'Hindouisme: Anthropologie d'une civilization. Paris: Flammarion.

Brass, P. (2003). The production of Hindu-Muslim violence in contemporary India. Seattle: University of Washington Press.

Braudel, F. (1989 [1987]). Gramática das civilizações. Lisboa: Teorema.

Corbridge, S., \& Harris, J. (2008 [2000]). Reinventing India: Liberalization, Hindu nationalism and popular democracy. Cambridge: Polity Press.

Dalton, D. (Ed.) (1996). Mahatma Gandhi: Selected political writings. Indianapolis: Hackett Publishing Company, Inc.

Elst, K. (1990). Ram Janmabhoomi vs. Babri Masjid: A case study in Hindu-Muslim conflict. Nova Deli: Voice of India.

Fukuyama, F. (1999[1992]). O fim da história e o último homem. Lisboa: Gradiva.

Gandhi, M. K. (2011 [1909]). Hind swaraj or Indian home rule. Disponível em http://www.arvindguptatoys. com/arvindgupta/hindswaraj.pdf

Golwalkar, M. S. (2000 [1966]). Bunch of thoughts. Bangalore: Sahitya Sindhu.

Golwalkar, M. S. (2006 [1939]). We or our nationhood defined. Nagpur: Bharat Publications.

Hanson, T. B. (1999). The saffron wave: Democracy and Hindu nationalism in modern India. Princeton. Nova Jérsia: Princeton University Press.

Huntington, S. P. (1999 [1996]). O choque das civilizações e a mudança na ordem mundial. Lisboa: Gradiva.

Jaffrelot, C. (Ed.) (2007). Hindu nationalism: A reader. Princeton: Princeton University Press.

Juergensmeyer, M. (1996). The debate over hindutva. Religion, 26(2), 129-136.

Leis de Manu. (1992). The laws of Manu. Nova Deli: Penguin Books.

Lichter, G., \& Bandyopadhyay, S. (2008). Indian cinema and the presentist use of history: Conceptions of "nationhood" in Earth and Laagan. Asian Survey, 48(3), 431-452.

Madan, T. N. (1987). Secularism in its place. The Journal of Asian Studies, 46(4), 747-759.
Madan, T. N. (1993). Whither Indian secularism?. Modern Asian Studies, 27(3), 667-697.

Malik, Y. K., \& Vajpeyi, D. K. (1989). The rise of Hindu militancy: India's secular democracy at risk. Asian Survey, 29(3), 308-325.

Mendes, L. F. C. (2009). Existe uma civilização hindu?. Janus. Disponível em http://janusonline. pt/2009/2009_3_3_6.html

Nussbaum, M. C. (2007). The clash within: Democracy, religious violence and India's future. Cambridge, Massachusetts: The Belknap Press of Harvard University Press.

Panikkar, K. N. (1999). Introduction. In K. N. Panikkar (Ed.), The concerned Indian's guide to communalism (pp. vii-xxxv). Nova Deli: Penguin Books.

Puniyani, R. (2005). Introduction: Religion, power and violence. In R. Puniyani (Ed.), Religion, power and violence: Expression of politics in contemporary times (pp. 12-26). Nova Deli: Sage Publications.

Rupam, J., \& Lasseter, T. (2018, 19 de março). Nacionalistas hindus criaram comissão para reescrever a história. Público (Reuters), pp. 24-25.

Rushdie, S. (2017, 05 de junho). Bienvenue dans l'ère de l'impossible. Philosophie Magazine, 8-14.

Saïd, E. W. (2002). O choque das ignorâncias. História, $41,26-31$.

Sarkar, T. (1999). The gender predicament. In K. N. Panikkar (Ed.), The concerned Indian's guide to communalism (pp. 131-159). Nova Deli: Penguin Books.

Savarkar, V. D. (1927). The Gandhian confusion. Pune: Himani Savarkar. Disponível em http://savarkarsmarak.com/bookdetails.php?bid $=81$

Savarkar, V. D. (1989 [1923]). Hindutva: Who is a Hindu?. Bombaim: Veer Savarkar Prakashan.

Steinmetz, G. (2007). Issues and agendas: The relations between sociology and history in the United States: The current state of affairs. Journal of Historical Sociology, 20(1/2), 1-12.

Van der Veer, P. (1987). "God must be liberated!": A hindu liberation movement in Ayodhya. Modern Asian Studies, 21(2), 283-301.

Wright Jr., T. P. (2001). The Muslim minority before and after Ayodhya. In A. Sharma (Ed.), Hinduism and secularism: After Ayodhya (pp. 1-24). Hampshire: Palgrave.

Recebido a 03/04/2018. Aceite para publicação a 10/10/2018.

Pedro Matias Santos (psantos@iscsp.ulisboa.pt). Docente da Unidade de Coordenação das Licenciaturas de Sociologia, Antropologia e Serviço Social e no Mestrado Sociedade, Risco e Saúde, no ISCSP, Universidade de Lisboa \& Investigador no Instituto do Oriente, unidade de investigação do ISCSP. 